\title{
Converting metal-organic framework particles from hydrophilic to hydrophobic by an interfacial assembling route
}

\author{
Fanyu Zhang, ${ }^{1,2}$ Xinxin Sang, ${ }^{1,2}$ Xiuniang Tan, ${ }^{1,2}$ Chengcheng Liu, ${ }^{1,2}$ Jianling Zhang, ${ }^{* 1,2}$ Tian \\ Luo, ${ }^{1}$ Lifei Liu, ${ }^{1,2}$ Buxing Han, ${ }^{1,2}$ Guanying Yang ${ }^{1}$ and Bernard P. Binks*3
}

\footnotetext{
${ }^{1}$ Beijing National Laboratory for Molecular Sciences, CAS Key Laboratory of Colloid, Interface and Chemical Thermodynamics, CAS Research/Education Center for Excellence in Molecular Sciences, Institute of Chemistry, Chinese Academy of Sciences, Beijing 100190, P.R. China ${ }^{2}$ School of Chemistry and Chemical Engineering, University of Chinese Academy of Sciences, Beijing 100049, P.R. China ${ }^{3}$ School of Mathematics and Physical Sciences, University of Hull, Hull HU6 7RX, UK
}

Submitted to Langmuir

*zhangjl@iccas.ac.cn; b.p.binks@hull.ac.uk

KEYWORDS: emulsion, interfacial assembling, metal-organic framework, hydrophilic, hydrophobic 
This document is the Accepted Manuscript version of a Published Work that appeared in final form in Langmuir copyright (c) American Chemical Society after peer review and technical editing by the publisher.

To access the final edited and published work see https://pubs.acs.org/doi/10.1021/acs.langmuir.7b02365 


\begin{abstract}
Here we propose to modify the hydrophilicity of metal-organic framework (MOF) particles by an interfacial assembling route, which is based on the surface-active nature of MOF particles. It was found that hydrophilic UiO-66- $\mathrm{NH}_{2}$ particles can be converted to hydrophobic particles through an oil-water interfacial assembling route. The underlying mechanism for the conversion of UiO-66- $\mathrm{NH}_{2}$ was investigated by X-ray photoelectron spectroscopy and FT-IR spectroscopy. It was revealed that the close assembly of $\mathrm{UiO}-66-\mathrm{NH}_{2}$ particles at the oil-water interface strengthens the coordination between organic ligands and metal ions, which results in a decrease in the proportion of hydrophilic groups on UiO-66- $\mathrm{NH}_{2}$ particle surfaces. Hydrophobic UiO-66$\mathrm{NH}_{2}$ particles show improved adsorption capacity for dyes in organic solvents compared with pristine UiO-66- $\mathrm{NH}_{2}$ particles. It is expected that the interfacial assembling route can be applied to the synthesis of different kinds of MOF materials with tunable hydrophilicity or hydrophobicity required for diverse applications.
\end{abstract}




\section{INTRODUCTION}

Recently, metal-organic frameworks (MOFs) have become of great interest in the field of materials because of their unique properties such as tunable composition, differing structures and morphologies, ultrahigh porosity and huge surface area ${ }^{1,2}$ which confer on them potential applications in gas storage, ${ }^{3,4}$ gas absorption and separation, ${ }^{5}$ drug delivery ${ }^{6,7}$ and catalysis. ${ }^{8-10}$ Up to now, the majority of MOFs have high affinity towards water, which largely restricts their open-air applications as promising materials. ${ }^{11}$ To solve this problem, many efforts have been devoted to reduce the affinity towards humidity and water and increase the hydrophobic character of MOFs. The commonly adopted methods are either functionalizing the MOF surface with hydrophobic ligands (e.g. alkyl functional groups ${ }^{11,12}$ or fluoro ligands ${ }^{13,14}$ ) or mixing MOFs with hydrophobic compounds (e.g. carbon, ${ }^{15-17}$ polydimethysiloxane, ${ }^{18}$ silica $^{19}$ or alumina ${ }^{20}$ ). Unfortunately, the introduction of functional ligands or a second phase in MOFs inevitably affects their structure, porosity and the accessibilty to the catalytic sites of the pristine MOF, thus lowering the adsorption capacity and catalytic activity.

Owing to the hybrid chemical compositions, MOFs have recently been shown to exhibit surface-activity. It has been reported that some MOFs can emulsify two immiscible liquids, like water and oil, water and hydrophobic ionic liquid, water and supercritical $\mathrm{CO}_{2}$, to produce particle-stabilised Pickering emulsions. ${ }^{21-27}$ Analogous to traditional emulsifiers, the MOF nanoparticles can assemble at the interface of the two immiscible phases to stabilize the emulsion droplets against coalescence. Interestingly, the structures and properties of the emulsions can be easily modulated by adjusting the metal ions and organic ligands of MOFs owing to their designable and tunable features. More interestingly, the MOF-stabilized emulsions provide a 
novel interfacial templating route for fabricating MOF materials. The MOF superstructures (e.g. 3D network and capsules) $)^{22-25}$ and MOF/polymer composites have been prepared from MOFstabilized emulsions. ${ }^{21,26}$ For all these studies, researchers focus their attention on the MOF morphologies as templated by emulsion droplets. No attention has been paid to tuning the hydrophilicity or hydrophobicity of MOFs by such a route. As is well recognized for surfactantstabilised emulsions, surface-active particles located at the oil-water interface have a distinct orientation in close proximity, ${ }^{28-30}$ different from their molecular dispersions in a single solvent. It is expected that the interfacial assembling of MOF particles with desirable amphiphilicity would exert an influence on the wettability of MOF particle surfaces, possibly through the interactions between particles and water, particles and oil and between particles.

Here we propose an interfacial assembling route for modifying the wettability of MOF particle surfaces. UiO-66- $\mathrm{NH}_{2}$, which is a prototypical $\mathrm{Zr}-\mathrm{MOF}$ with excellent thermal, aqueous, acid stability and potential applications in a variety of fields, ${ }^{31-33}$ was studied. By an oil-water interfacial assembling route, hydrophilic $\mathrm{UiO}-66-\mathrm{NH}_{2}$ particles can be converted to hydrophobic particles. The possible mechanism for this interesting phenomenon was investigated by X-ray photoelectron spectroscopy (XPS) and FT-IR spectroscopy. The hydrophobic UiO-66-NH2 particles have been utilized as absorbent for dyes in organic solvents, which show improved adsorption capacities compared with pristine $\mathrm{UiO}-66-\mathrm{NH}_{2}$ particles. It is worth noting that the interfacial assembling route only changes the surface properties of MOF particles and involves no additional compounds or functional ligands in the modified MOF. Consequently, the intrinsic properties of MOF can be retained, which is very important for their applications in different fields.

\section{EXPERIMENTAL}


2.1. Materials. 2-aminoterephthalic acid (99\%) was purchased from Alfa Aesar. Zirconium tetrachloride (99.5\%) was produced by Strem Chemicals. Sudan Orange G (97\%) was supplied by J \& K Scientific Co., Ltd. N,N-dimethylformamide (DMF, 99.7\%), cyclohexane (99.7\%), hexane (99.5\%) and deionized water were provided by Beijing Chemical Works.

2.2. UiO-66- $\mathrm{NH}_{2}$ synthesis. For the synthesis of UiO-66- $\mathrm{NH}_{2}, \mathrm{ZrCl}_{4}(0.240 \mathrm{~g})$ and 2aminoterephthalic acid (0.186 g) were added into DMF (60 mL), followed by water $(0.19 \mathrm{~mL})$. The above mixture was sealed and heated at $120{ }^{\circ} \mathrm{C}$ for $24 \mathrm{~h}$. The product was obtained by filtration, washing with DMF and methanol and drying in vacuum at $60{ }^{\circ} \mathrm{C}$ for $12 \mathrm{~h}$.

2.3. Emulsion formation and characterization. Emulsification was performed using a Shanghai Zhisun JYD-150 sonicator. The desired amount of UiO-66- $\mathrm{NH}_{2}$ powder was added into a mixture of water and cyclohexane (v/v 1:1) in a glass vial. The sonic frequency was 20 $\mathrm{kHz}$ with the output power at $45 \mathrm{~W}$. 5 min sonication was applied for emulsification. To avoid localized overheating, a $20 \mathrm{~s}$ break after each $5 \mathrm{~s}$ of sonication was applied. The emulsion was characterized using an Olympus FV1000-IX81 confocal laser scanning microscope (CLSM) with an excitation wavelength of $559 \mathrm{~nm} .5 \mu \mathrm{L}$ of freshly prepared emulsion containing Rhodamine B $\left(10^{-4} \mathrm{~mol} \mathrm{~L}^{-1}\right)$ was carefully placed on a $0.7 \mathrm{~mm}$ thick cover slip at room temperature, and the images were captured by a digital CCD.

2.4. Characterisation of modified particles. The vessel containing a cyclohexane-in-water emulsion was placed into liquid nitrogen $\left(-196^{\circ} \mathrm{C}\right)$ and the liquids were removed using Freeze Drier FD-1A-50 (Beijing Tianlinhengtai Technology Co., Ltd.). The solid obtained was characterized by scanning electron microscopy (SEM) using a Hitachi S-4800 instrument and Xray diffraction (XRD) performed on a Rigaku $\mathrm{D} / \mathrm{max}-2500$ diffractometer with $\mathrm{CuK} \alpha$ radiation $(\lambda=1.5418 \AA)$ at $40 \mathrm{kV}$ and $200 \mathrm{~mA}$. The porosity properties were derived from $\mathrm{N}_{2}$ adsorption- 
desorption isotherms at $77 \mathrm{~K}$ using a Quadrasorb SI-MP system. Contact angle measurements were performed at $25{ }^{\circ} \mathrm{C}$ using a contact angle meter (Harke-SPCAX1) by placing a water droplet $(10 \mu \mathrm{L})$ on the surface of the UiO-66- $\mathrm{NH}_{2}$ film in air. The UiO-66- $\mathrm{NH}_{2}$ film was prepared by a tablet machine at a pressure of $10 \mathrm{kPa}$ for $20 \mathrm{sec}$ with a $30 \mathrm{mg}$ sample. XPS data of the pristine and modified UiO-66- $\mathrm{NH}_{2}$ particles were obtained with an ESCALab 220i-XL instrument from VG Scientific using $300 \mathrm{~W}$ AlK $\alpha$ radiation. The base pressure was $3 \times 10^{-9}$ mbar. The binding energies were referenced to the C1s line at $284.8 \mathrm{eV}$ from adventitious carbon. FTIR spectra of the pristine and modified UiO-66- $\mathrm{NH}_{2}$ particles were obtained using a Bruker Tensor 27 spectrometer.

2.5. Dispersion of modified UiO-66- $\mathrm{NH}_{2}$ particles in water-hexane mixture. The desired amount of the modified $\mathrm{UiO}-66-\mathrm{NH}_{2}$ particles was added to a water and hexane mixture (v/v 1:1) in glass vials. The UiO-66- $\mathrm{NH}_{2}$ concentration was $1.71 \mathrm{mg} \mathrm{mL}^{-1}$ relative to the total volume. The mixture was stirred using a magnetic stirrer for 3 min and the phase behavior was observed.

2.6. Dye adsorption. A desired amount of Sudan Orange $\mathrm{G}$ solution in hexane $(5 \mathrm{~mL}$, 4.6 $\times 10^{-5} \mathrm{~mol} \mathrm{~L}^{-1}$ ) was placed in a $50 \mathrm{~mL}$ centrifuge tube, followed by adding $\mathrm{UiO}-66-\mathrm{NH}_{2}$ solid (10 mg). Then the mixture was stirred for different times. After centrifugation, the concentration of dye in the supernatant was determined using a Shimadzu UV-2450 UV-Vis spectrophotometer. The concentration of dye adsorbed was calculated from the absorbance of Sudan Orange G using the calibration curve. Using pseudo-first order and pseudo-second order kinetic models, the experimental data were fitted by eq. (1) and (2) to explore the potential rate-controlling step in the adsorption of Sudan Orange G onto UiO-66- $\mathrm{NH}_{2}$ particles, ${ }^{34}$

$$
\begin{aligned}
& \ln \left(q_{e}-q_{t}\right)=\ln \left(q_{e}\right)-k_{1} t \\
& t / q_{t}=1 /\left(k_{2} q_{e}{ }^{2}\right)+t / q_{e}
\end{aligned}
$$


where $q_{e}$ and $q_{t}$ denote the amounts of dye adsorbed by the adsorbent $\left(\mathrm{mg} \mathrm{g}^{-1}\right)$ at equilibrium and at time $t$, respectively. $k_{1}$ and $k_{2}$ are first and second order rate constants respectively.

\section{RESULTS AND DISCUSSION}

3.1. Emulsion formation. The pristine $\mathrm{UiO}-66-\mathrm{NH}_{2}$ particles were first prepared by a hydrothermal method. ${ }^{35}$ Then the desired amount of the pre-formed UiO-66- $\mathrm{NH}_{2}$ was added into a mixture of equal volumes of water and cyclohexane (14.29, 7.27, 4.69, 1.94 and $1.58 \mathrm{mg} \mathrm{mL}^{-}$

${ }^{1}$ ), followed by ultrasonication. Figure 1a-e shows the photographs of the as-prepared emulsions stabilized by UiO-66- $\mathrm{NH}_{2}$ particles, which have a turbid and milky appearance. The morphologies of the emulsions were characterized by CLSM using Rhodamine B as a probe (Figures 1f-j). The spherical droplets were identified as oil-in-water. It is easily understood that the UiO-66- $\mathrm{NH}_{2}$ particles are more hydrophilic, favoring the formation of a water-continuous emulsion. It is noted that for the emulsion with $\mathrm{UiO}-66-\mathrm{NH}_{2}$ concentration $14.29 \mathrm{mg} \mathrm{mL}^{-1}$, Rhodamine B molecules are completely adsorbed at the interface of droplets (Figure 1f) due to the strong adsorption of UiO-66- $\mathrm{NH}_{2}$ to Rhodamine $\mathrm{B}$ at such a high concentration. ${ }^{36}$ The droplet sizes of the emulsions range from 2-25 $\mu \mathrm{m}$ and roughly decrease with increasing UiO66- $\mathrm{NH}_{2}$ concentration. As the particle concentration becomes lower than $1.58 \mathrm{mg} \mathrm{mL}^{-1}$, water and oil cannot be emulsified by UiO-66- $\mathrm{NH}_{2}$ particles. 

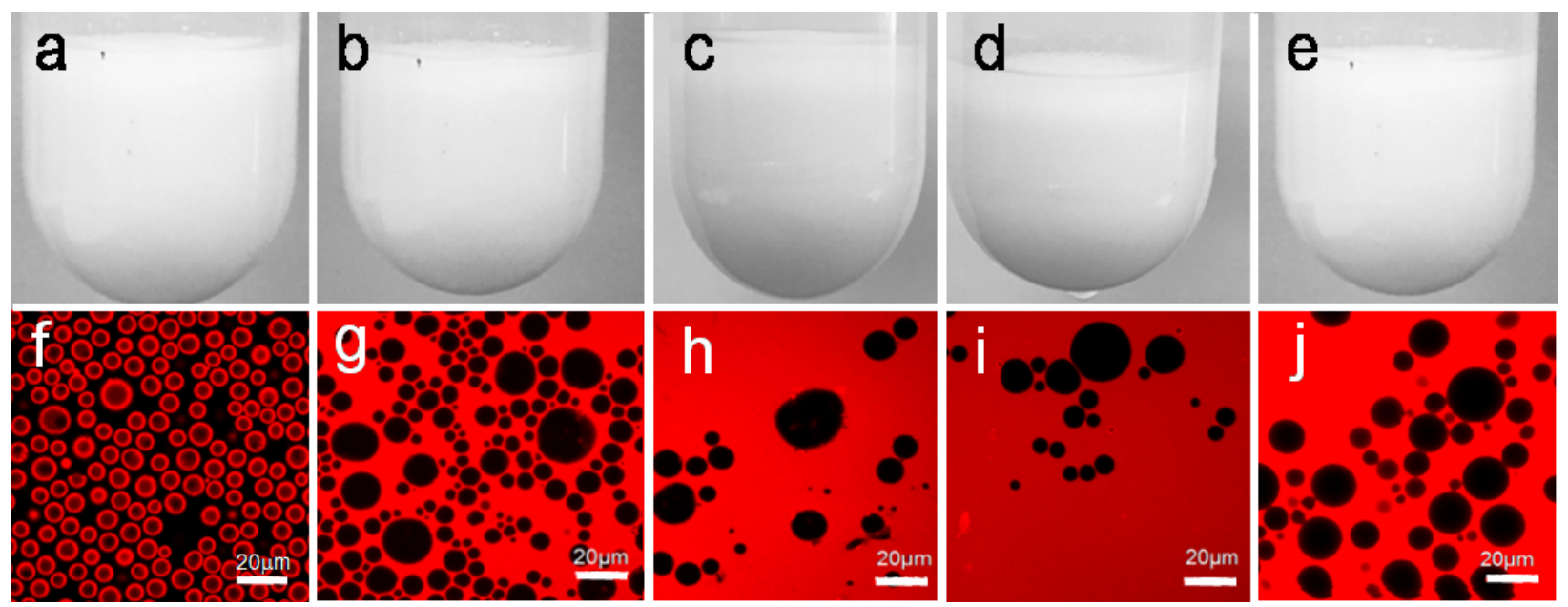

Figure 1. Photographs and CLSM images of cyclohexane-in-water emulsions stabilised by UiO-66- $\mathrm{NH}_{2}$ particles at concentrations $\left(\mathrm{mg} \mathrm{mL}^{-1}\right.$ ) of (a, f) 14.29, (b, g) 7.27, (c, h) 4.69, (d, i) 1.94 and (e, j) 1.58. Scales bars: $20 \mu \mathrm{m}$.

\subsection{Morphologies of the modified UiO-66- $\mathrm{NH}_{2}$ particles. The pristine UiO-66- $\mathrm{NH}_{2}$} particles prepared by a hydrothermal method consist of polyhedral nanocrystals around $100 \mathrm{~nm}$ in size (Figures 2a and b). The SEM images of the UiO-66- $\mathrm{NH}_{2}$ particles derived from the emulsion stabilised at a particle concentration of $1.58 \mathrm{mg} \mathrm{mL}^{-1}$ are shown in Figure 2c-e. Capsules of diameter approx. $20 \mu \mathrm{m}$ were formed, with thin walls composed of nanoparticles of around $80 \mathrm{~nm}$ in a single layer. The formation of $\mathrm{UiO}-66-\mathrm{NH}_{2}$ capsules from the pristine dispersed particles can be ascribed to the templating effect of emulsion droplets, ${ }^{23,25}$ which are stabilized by UiO-66- $\mathrm{NH}_{2}$ particles assembled at the oil-water interface. Comparing Figure 2e with $2 \mathrm{~b}$, it is evident that the modified UiO-66- $\mathrm{NH}_{2}$ nanoparticles are a little smaller and smoother than the pristine polyhedrons. The results show that the interfacial templating route not only induces the assembly of UiO-66- $\mathrm{NH}_{2}$ particles into capsules, but also influences the particle size and morphology. The XRD pattern of modified UiO-66- $\mathrm{NH}_{2}$ particles is identical with that 
of pristine particles (Figure 3), indicating that the crystalline structure of UiO-66- $\mathrm{NH}_{2}$ remains unchanged. The $\mathrm{N}_{2}$ adsorption-desorption isotherms reveal that modified UiO-66- $\mathrm{NH}_{2}$ particles have similar Brunauer-Emmett-Teller (BET) surface area and pore volume as those of pristine UiO-66- $\mathrm{NH}_{2}$ particles (Figure $\mathrm{S} 1$ in Supporting Information), proving the absence of additional compounds or functional ligands in the modified MOF.

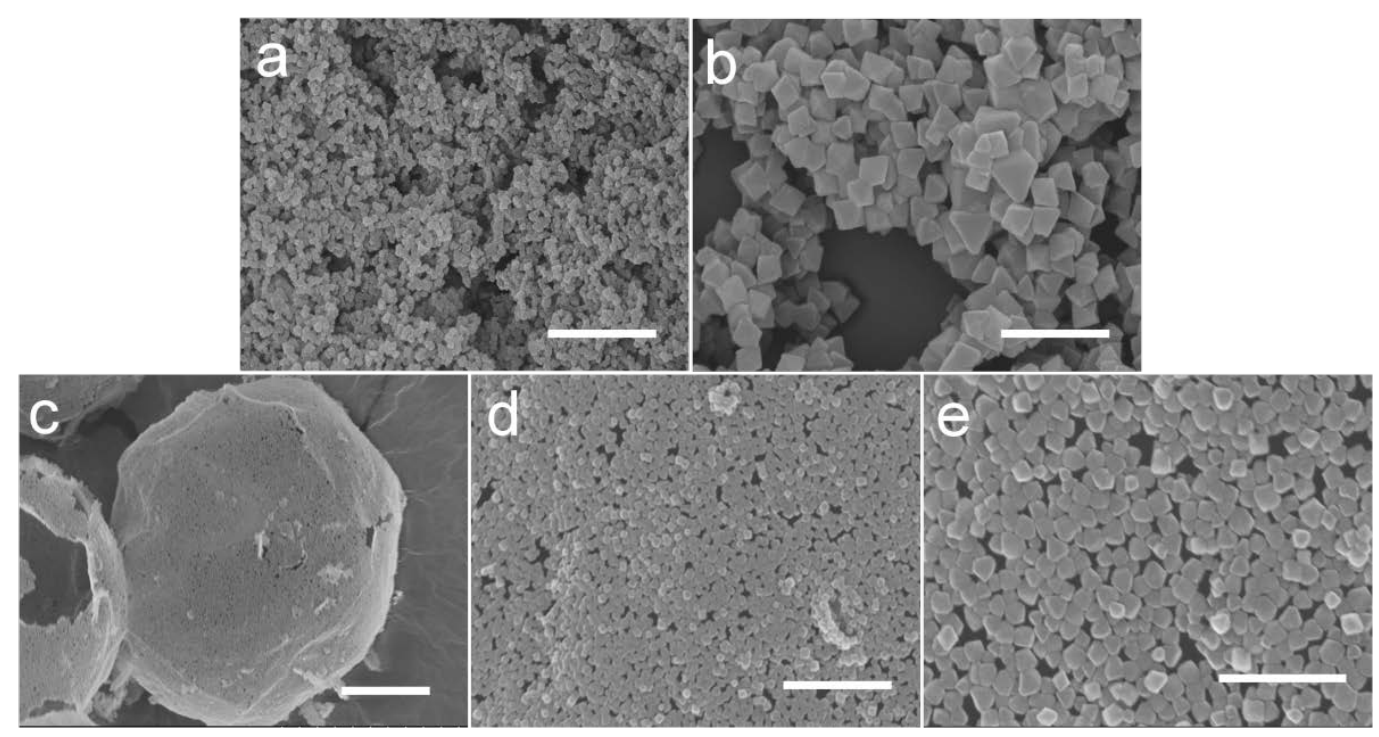

Figure 2. SEM images of (a, b) pristine UiO-66- $\mathrm{NH}_{2}$ particles and (c-e) modified UiO-66- $\mathrm{NH}_{2}$ particles after freeze drying a cyclohexane-in-water emulsion containing $1.58 \mathrm{mg} \mathrm{mL}^{-1}$ of particles relative to the total volume of oil plus water. Scale bars: $1 \mu \mathrm{m}$ in a and d, $500 \mathrm{~nm}$ in b and e, $5 \mu \mathrm{m}$ in c.

The UiO-66- $\mathrm{NH}_{2}$ hollow capsules covered by nanoparticles were also obtained from other emulsions with different particle concentrations (Figure S2 in Supporting Information). All the XRD patterns of the modified UiO-66- $\mathrm{NH}_{2}$ particles are identical with that of pristine UiO-66$\mathrm{NH}_{2}$ particles (Figure 3). 


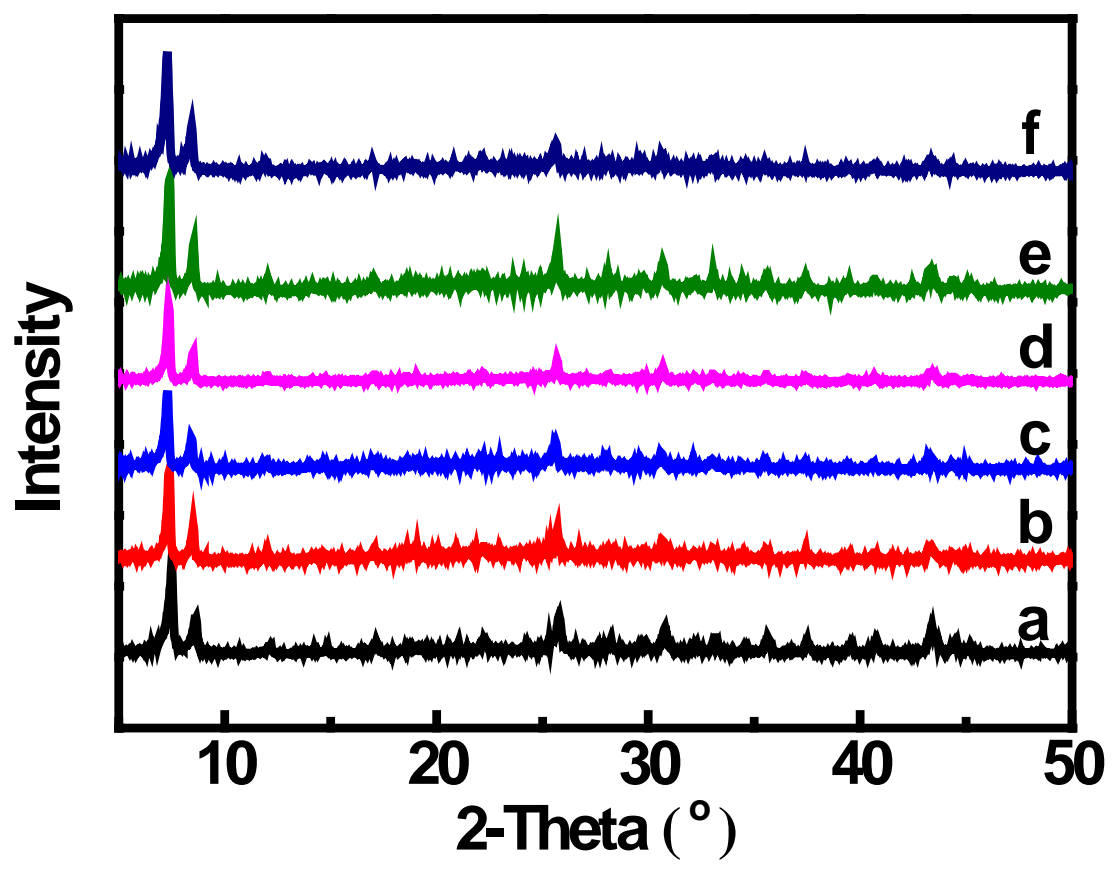

Figure 3. XRD patterns of (a) pristine UiO-66- $\mathrm{NH}_{2}$ particles and (b-f) modified UiO-66$\mathrm{NH}_{2}$ particles obtained from emulsions at particle concentrations (mg mL ${ }^{-1}$ ) of (b) 14.29 , (c) 7.27 , (d) 4.69, (e) 1.94 and (f) 1.58 .

3.3 Wettabilities of modified UiO-66- $\mathrm{NH}_{2}$ particles. The wettabilities in air of the different UiO-66- $\mathrm{NH}_{2}$ particles were measured through the aqueous phase by static contact angle measurements. Pristine UiO-66- $\mathrm{NH}_{2}$ exhibits a contact angle of around $29^{\circ}$ (Figure 4a), indicative of a reasonably hydrophilic surface. For the modified UiO-66- $\mathrm{NH}_{2}$, the contact angle increases as the initial concentration of particles in the emulsion decreases (Figures 4b-f), implying increased hydrophobicity. The contact angles of modified UiO-66- $\mathrm{NH}_{2}$ from emulsions with particle concentrations of 1.94 and $1.58 \mathrm{mg} \mathrm{mL}^{-1}$ reach values higher than $90^{\circ}$, showing that these two modified MOFs are relatively hydrophobic. 


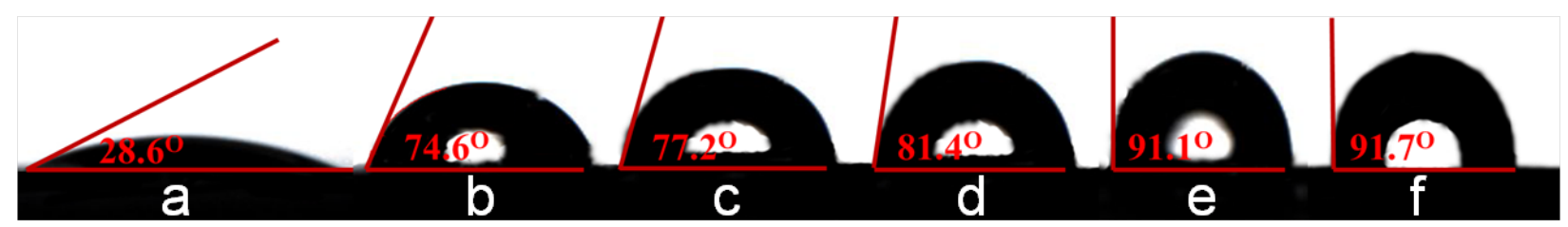

Figure 4. Photos of water drops in air on films of UiO-66- $\mathrm{NH}_{2}$ particles for (a) pristine particles and (b-f) modified particles obtained from emulsions with $\mathrm{UiO}-66-\mathrm{NH}_{2}$ particle concentration of 14.29, 7.27, 4.69, 1.94 and $1.58 \mathrm{mg} \mathrm{mL}^{-1}$, respectively.

\subsection{Dispersion of modified UiO-66- $\mathrm{NH}_{2}$ particles in oil plus water mixture. The}

hydrophilic-to-hydrophobic conversion of $\mathrm{UiO}-66-\mathrm{NH}_{2}$ nanocrystals can be further proved by redispersing them in a 1:1 water and $n$-hexane mixture (Figure 5). The pristine UiO-66- $\mathrm{NH}_{2}$ particles are preferentially dispersed in water as expected (photo a). For photos b and c, a small percentage of particles transfer to the upper oil phase because of the increased hydrophobicity. For photo d, similar amounts become dispersed in both oil and water phases, while UiO-66-NH 2 particles become completely dispersed in the oil phase for photos e and f. The transfer of UiO66- $\mathrm{NH}_{2}$ nanocrystals from water to oil is in agreement with their progressive hydrophilic-tohydrophobic conversion.
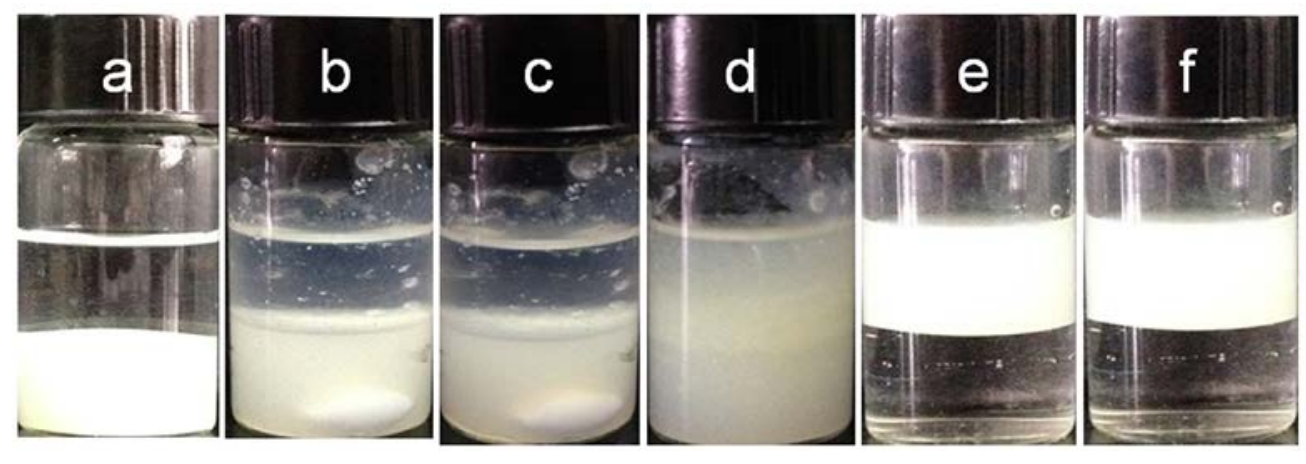
Figure 5. Appearance of particle dispersions in 1:1 water-hexane mixture at equilibrium for (a) pristine UiO-66- $\mathrm{NH}_{2}$ particles and (b-f) modified UiO-66- $\mathrm{NH}_{2}$ particles obtained from emulsions with UiO-66- $\mathrm{NH}_{2}$ particle concentration of 14.29, 7.27, 4.69, 1.94 and $1.58 \mathrm{mg} \mathrm{mL}^{-1}$, respectively. The particle concentration is $1.71 \mathrm{mg} \mathrm{mL}^{-1}$ relative to the total volume of water plus hexane.

3.5. XPS study. To probe the mechanism of the hydrophilic-to-hydrophobic conversion of UiO-66- $\mathrm{NH}_{2}$ particles, XPS was performed on pristine and modified UiO-66- $\mathrm{NH}_{2}$ particles (Figures S3 and S4 in Supporting Information). As an example, Figure 6a shows the XPS spectrum of the modified UiO-66- $\mathrm{NH}_{2}$ particles from the emulsion prepared with $1.58 \mathrm{mg} \mathrm{mL}^{-1}$ of particles (the most hydrophobic), from which the elemental content of the particle surface can be determined. As shown in Figure 6b, the contents of elemental zirconium, oxygen and nitrogen on the surface of modified particles are lower than those in pristine particles and decrease with an increase in their hydrophobicity (i-v). Meanwhile, the content of elemental carbon displays an opposite trend. By fitting C1s XPS spectra, three types of carbon bond can be derived, i.e. C-C or $\mathrm{C}=\mathrm{C}(284.8 \mathrm{eV}), \mathrm{C}-\mathrm{O}$ or C-N (286.3 eV) and COOH (288.7 eV) (Figure 6c). ${ }^{37,38}$ The percentages of each bonding state of carbon in pristine and modified UiO-66- $\mathrm{NH}_{2}$ particles are shown in Figure $6 \mathrm{~d}$. The contents for $\mathrm{C}-\mathrm{C} / \mathrm{C}=\mathrm{C}$ of the modified UiO-66- $\mathrm{NH}_{2}$ are higher than that of pristine UiO-66- $\mathrm{NH}_{2}$ and increase with an increase in their hydrophobicity, while the contents for $\mathrm{C}-\mathrm{O} / \mathrm{C}-\mathrm{N}$ and $\mathrm{COOH}$ show an opposite trend. Particularly, the proportion of hydrophilic groups $\mathrm{C}-\mathrm{O} / \mathrm{C}-\mathrm{N}$ and $\mathrm{COOH}$ on the surface of the modified $\mathrm{UiO}-66-\mathrm{NH}_{2}$ particles from an emulsion with a particle concentration of $1.58 \mathrm{mg} \mathrm{mL}^{-1}$ is much less than that on pristine 
particles. The XPS results reveal that the surface compositions of the UiO-66- $\mathrm{NH}_{2}$ particles were changed by the interfacial templating route, which has a direct consequence on their wettability.
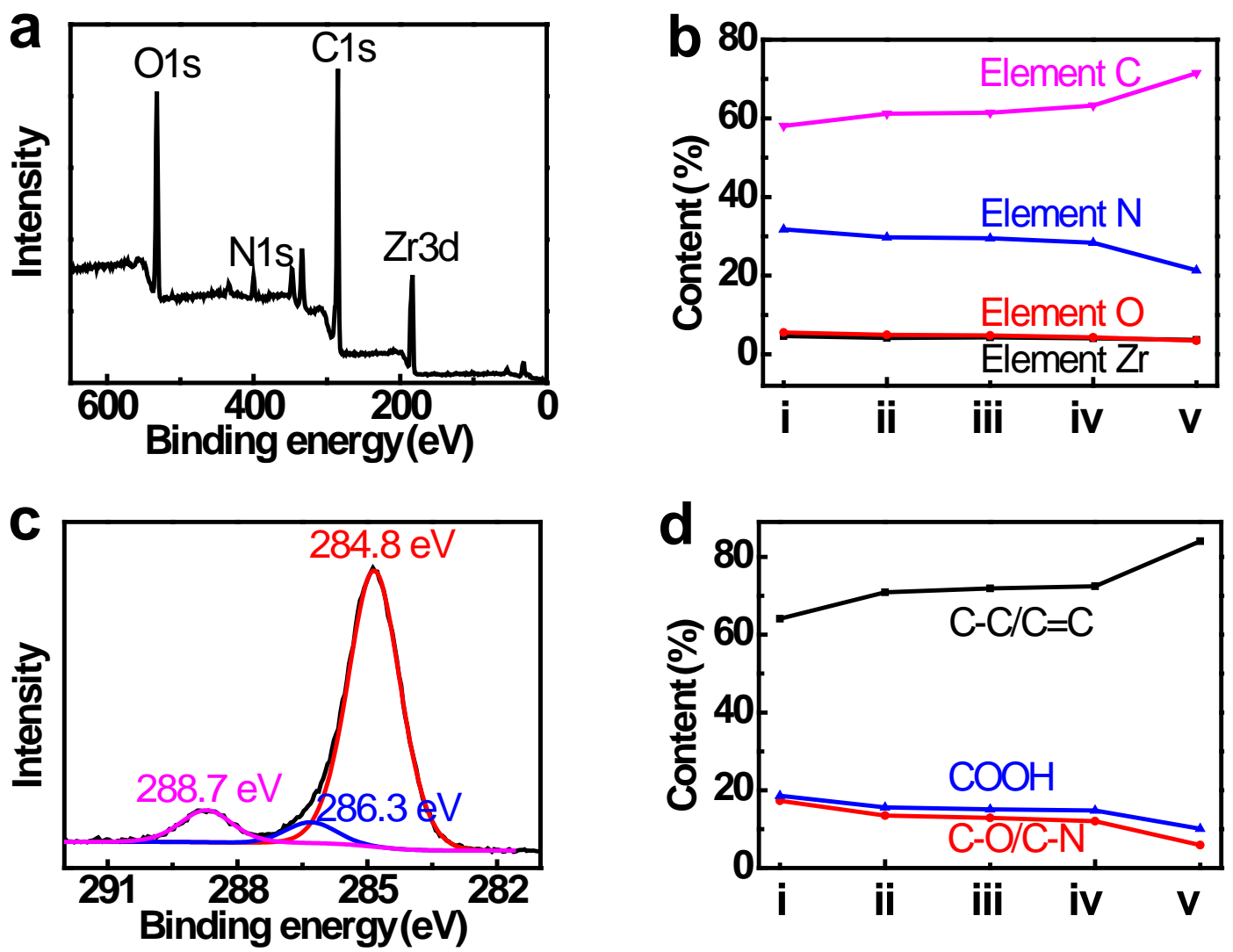

Figure 6. (a) Wide-range XPS and (c) C1s XPS spectra of modified UiO-66- $\mathrm{NH}_{2}$ particles obtained from an emulsion with particle concentration $1.58 \mathrm{mg} \mathrm{mL}^{-1}$. (b) Surface element contents and (d) three style carbon bond contents for (i) pristine UiO-66- $\mathrm{NH}_{2}$ and (ii-v) modified UiO-66- $\mathrm{NH}_{2}$ from emulsions with particle concentrations of 14.29, 7.27, 4.69 and $1.58 \mathrm{mg} \mathrm{mL}^{-1}$, respectively.

3.6. FT-IR spectra. To better understand the underlying mechanism for the elemental changes on particle surfaces, FT-IR spectra of the pristine and modified UiO-66- $\mathrm{NH}_{2}$ particles were measured (Figure 7).The absorption bands at 3358 and $3460 \mathrm{~cm}^{-1}$ of the pristine UiO-66- 
$\mathrm{NH}_{2}$ correspond to the symmetric and asymmetric vibrations of $-\mathrm{NH}_{2}$ groups on the organic linker. For the modified UiO-66- $\mathrm{NH}_{2}$, these two bands shift to higher wavenumbers, especially for that obtained from the emulsion with the lowest particle concentration of $1.58 \mathrm{mg} \mathrm{mL}^{-1}$, e.g. 3371 and $3465 \mathrm{~cm}^{-1}$ in spectrum e. It implies that some bonding between the amino groups in the coordinated acid with $\mathrm{C}=\mathrm{O}$ groups of free organic ligand are broken. ${ }^{39,40}$ This is consistent with the strengthened interaction between $\mathrm{COO}^{-}$and $\mathrm{Zr}^{4+}$. The intensity of the absorption band at $1573 \mathrm{~cm}^{-1}$ corresponding to the interaction of $\mathrm{COO}^{-}$with $\mathrm{Zr}^{4+}$ increases gradually for the modified particles of increased hydrophobicity relative to the intensity of the absorption band at $1656 \mathrm{~cm}^{-1}$, which results from the carboxyl group of non-bound aromatic carboxylic acid. ${ }^{41} \mathrm{It}$ indicates that more $\mathrm{COO}^{-}$interact with $\mathrm{Zr}^{4+}$ for the modified UiO-66- $\mathrm{NH}_{2}$ particles, especially for the modified UiO-66- $\mathrm{NH}_{2}$ obtained from the emulsion at lower concentration. Therefore, the hydrophilicity of the modified UiO-66- $\mathrm{NH}_{2}$ particles is reduced due to a progressive reduction in the amount of free aromatic carboxylic acid on particle surfaces.

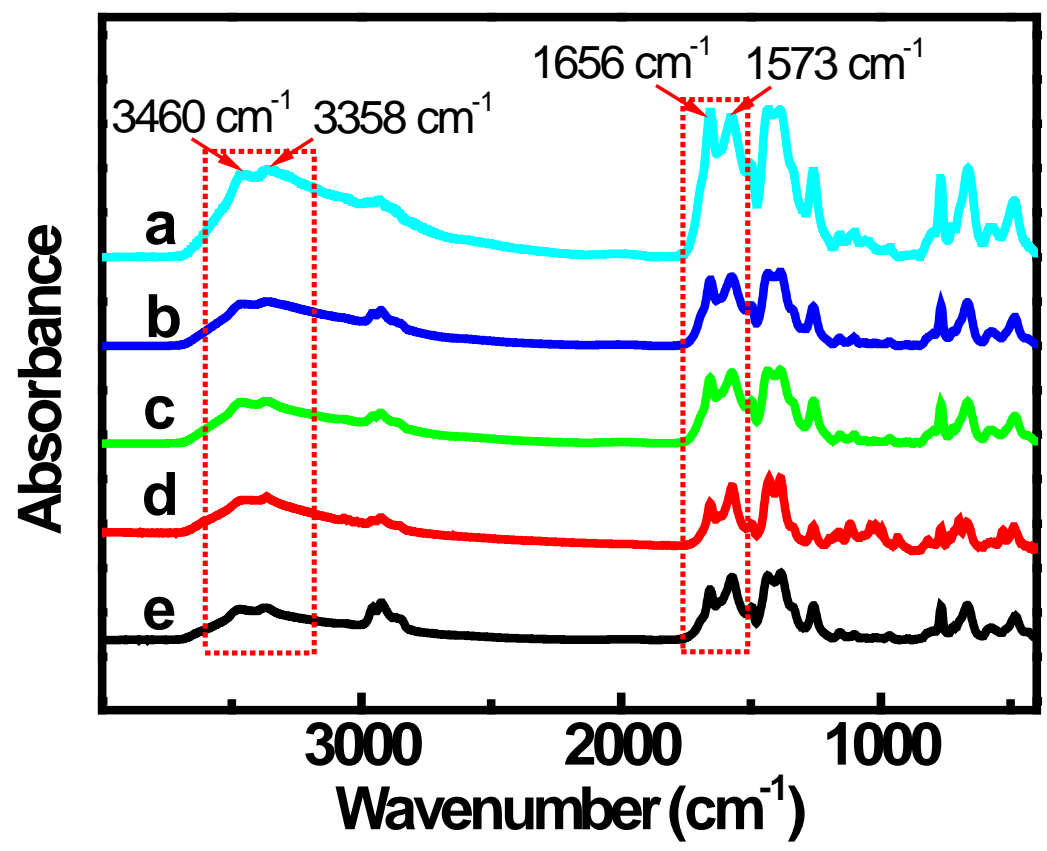


Figure 7. FT-IR spectra of (a) pristine UiO-66- $\mathrm{NH}_{2}$ and (b-e) modified UiO-66- $\mathrm{NH}_{2}$ particles obtained from emulsions with particle concentrations of 14.29, 7.27, 4.69 and $1.58 \mathrm{mg} \mathrm{mL}^{-1}$, respectively.

3.7. Proposed mechanism. Based on the above results, a mechanism for the hydrophilic-tohydrophobic conversion of UiO-66- $\mathrm{NH}_{2}$ particles induced upon assembly at the oil-water interface is proposed (Scheme 1). The structure of UiO-66- $\mathrm{NH}_{2}$ consists of an inner $\mathrm{Zr}_{6} \mathrm{O}_{4}(\mathrm{OH})_{4}$ core. ${ }^{42}$ Bridged by carboxylates (-COO-) from 2-aminoterephthalic acid, all of the polyhedron edges form a $\mathrm{Zr}_{6} \mathrm{O}_{4}(\mathrm{OH})_{4}\left(\mathrm{CO}_{2}\right)_{12}$ cluster. Each zirconium atom is eight-coordinated forming a square-antiprismatic coordination consisting of eight oxygen atoms (a in Scheme 1). UiO-66$\mathrm{NH}_{2}$ particles are hydrophilic due to the existence of many hydrophilic groups, e.g. $-\mathrm{NH}_{2}$ and $\mathrm{COOH}$ on particle surfaces which are charged. By forming emulsions at low enough UiO-66$\mathrm{NH}_{2}$ concentrations (e.g. 1.58 and $1.94 \mathrm{mg} \mathrm{mL}^{-1}$ ), all the UiO-66- $\mathrm{NH}_{2}$ nanocrystals assemble closely at the oil-water interface of emulsion drops (b in Scheme 1). The immense interface caters for the super-refinement demand of the MOF, ${ }^{43}$ which in turn can stabilize the emulsion in a better fashion. Therefore, the modified UiO-66- $\mathrm{NH}_{2}$ nanoparticles are smaller and smoother than the pristine polyhedrons, as evidenced by TEM images. none of this makes sense and ref. 43 is on exfoliation which has nothing to do with MOFs? what do you want to say? Such a modification of nanoparticles at the interface favors the close connection between particles and the coordination of - $\mathrm{COO}^{-}$groups with $\mathrm{Zr}^{4+}$ ions. As a consequence, the availability of hydrophilic groups on particle surfaces is reduced, which results in the conversion from hydrophilic to hydrophobic particles (c in Scheme 1). At higher concentration of UiO-66- $\mathrm{NH}_{2}$ particles (e.g. 7.27 and $14.29 \mathrm{mg} \mathrm{mL}^{-1}$ ), excess particles appear in the continuous phase $\mathrm{e}^{28}$ and 
their surfaces cannot be modified without the aid of an interface. Therefore, the hydrophilicity decrease of the UiO-66- $\mathrm{NH}_{2}$ particles obtained at higher concentration is smaller.

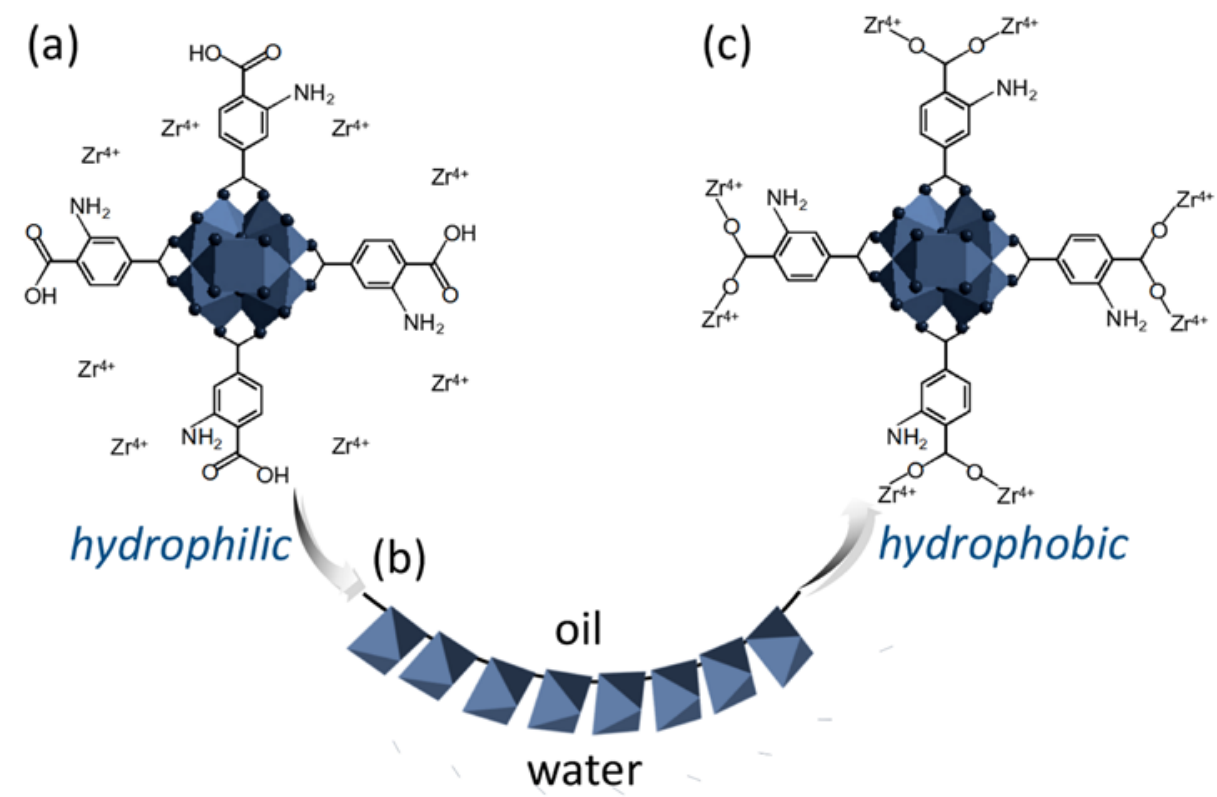

Scheme 1. Mechanism of the (a) hydrophilic to (c) hydrophobic conversion of UiO-66- $\mathrm{NH}_{2}$ particles by interfacial assembly (b).

3.8. Adsorption capability. MOFs have been widely used for the adsorption of pollutants in water due to their hydrophilicity. ${ }^{44,45}$ As is well known, there is a lot of demand for the clean-up of organic waste produced from various industrial processes. Here modified UiO-66- $\mathrm{NH}_{2}$ particles can be considered as an adsorbent in organic solvents owing to their increased hydrophobicity. The adsorption of Sudan Orange G in hexane $\left(4.6 \times 10^{-5} \mathrm{~mol} \mathrm{~L}^{-1}\right)$ by modified UiO-66- $\mathrm{NH}_{2}$ particles as well as pristine particles was studied. After a set time, the concentration of free Sudan Orange G in hexane was determined using UV-vis spectrophotometry ${ }^{45}$ (Figures S5-S7 and Table S1 in Supporting Information). As seen, the adsorption capability of modified UiO-66- $\mathrm{NH}_{2}$ particles is higher than that of pristine particles and increases with an increase in 
their hydrophobicity (Figure 8a). For example, 93\% of Sudan Orange G can be adsorbed by the modified UiO-66- $\mathrm{NH}_{2}$ particles obtained from an emulsion containing $1.58 \mathrm{mg} \mathrm{mL}^{-1}$ of particles within 3 min, while only 38\% Sudan Orange G was adsorbed by the pristine particles. The adsorption of Sudan Orange G on UiO-66- $\mathrm{NH}_{2}$ follows pseudo-second order kinetics (Figure 8b). The rate constant $k$ in the case of the most hydrophobic modified UiO-66- $\mathrm{NH}_{2}$ is $1.98 \mathrm{~g} \mathrm{mg}^{-1}$ $\mathrm{min}^{-1}$, which is three times higher than that of pristine particles $\left(0.48 \mathrm{~g} \mathrm{mg}^{-1} \mathrm{~min}^{-1}\right)$. Upon adsorption equilibrium, the adsorption capacity (i.e. the amount of dye adsorbed per gram of adsorbent) of the most hydrophobic modified UiO-66- $\mathrm{NH}_{2}$ reaches $4.61 \mathrm{mg} \mathrm{g}^{-1}$, much higher than that of pristine particles $\left(2.11 \mathrm{mg} \mathrm{g}^{-1}\right)$.

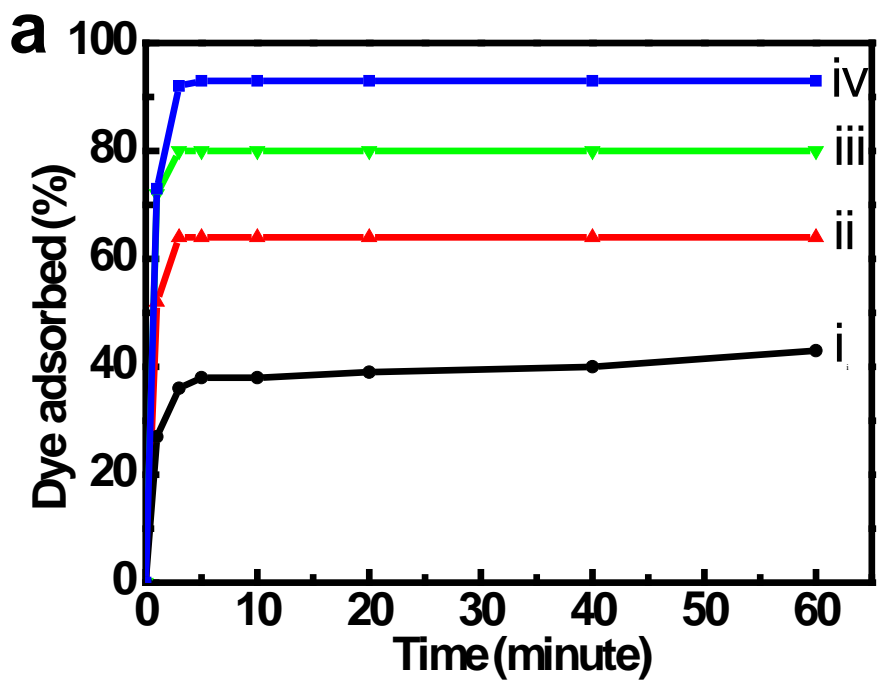




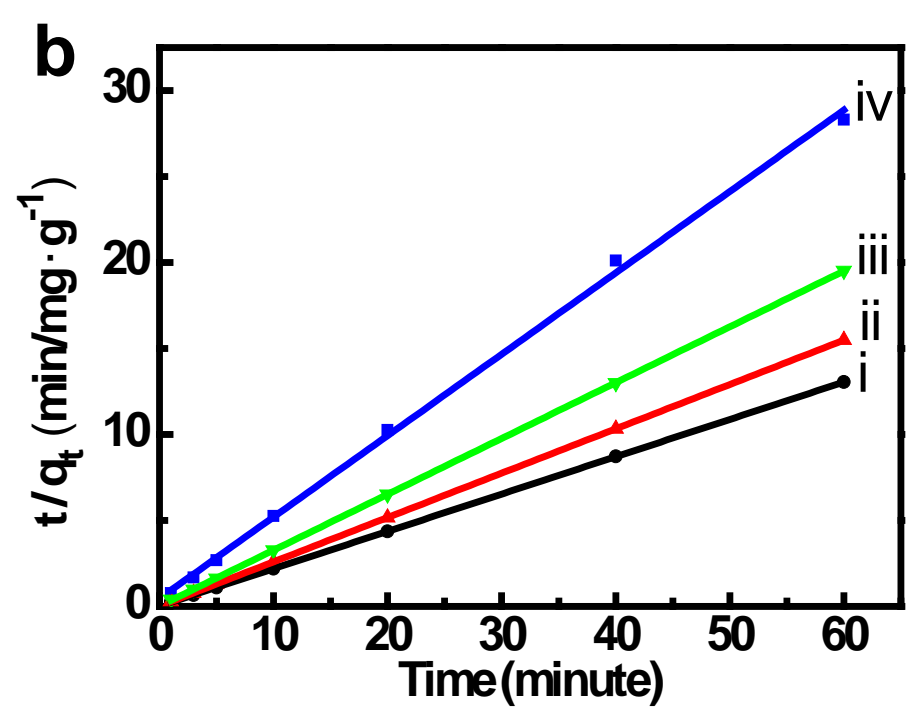

Figure 8 (a) Percentage of Sudan Orange G adsorbed onto UiO-66- $\mathrm{NH}_{2}$ particles in hexane versus time for (i) pristine $\mathrm{UiO}-66-\mathrm{NH}_{2}$ and (ii-iv) modified $\mathrm{UiO}-66-\mathrm{NH}_{2}$ obtained from emulsions with particle concentration of $14.29,4.69$ and $1.58 \mathrm{mg} \mathrm{mL}^{-1}$, respectively. (b) Pseudosecond order plots for the same particles.

\section{CONCLUSIONS}

In summary, we propose an interfacial assembling route to adjust the wettability of MOF particles, which is based on their surface-active nature and ability to assemble at an oil-water interface. It was found that hydrophilic UiO-66- $\mathrm{NH}_{2}$ can be converted to hydrophobic by this interfacial assembling route. The mechanism of the conversion was revealed to be related to the strengthened coordination between organic ligands and metal ions at the interface, which results in a decrease in the proportion of hydrophilic groups on UiO-66- $\mathrm{NH}_{2}$ particle surfaces. The modified UiO-66- $\mathrm{NH}_{2}$ particles have shown predominantly improved adsorption capacity for dyes in an organic solvent. We anticipate that this facile, easily controlled and versatile route can 
be applied to the synthesis of different kinds of MOF materials with tunable hydrophilicity or hydrophobicity required for applications in chemical reactions and adsorption processes.

\section{Supporting Information}

The Supporting Information is available free of charge on the ACS Publications website at $\operatorname{xxxxxxx.}$

Additional figures (PDF)

- AUTHOR INFORMATION

Corresponding Authors

*E-mail: zhangjl@iccas.ac.cn; b.p.binks@hull.ac.uk

Notes

The authors declare no competing financial interest

- ACKNOWLEDGEMENT

We thank financial support from the Ministry of Science and Technology of China (2017YFA0403003), National Natural Science Foundation of China (21525316, 21673254) and Chinese Academy of Sciences (QYZDY-SSW-SLH013). 


\section{REFERENCES}

(1) Yaghi, O. M.; O'Keeffe, M.; Ockwig, N. W.; Chae, H. K.; Eddaoudi M.; Kim, J. Reticular synthesis and the design of new materials. Nature 2003, 423, 705-714.

(2) Furukawa, H.; Cordova, K. E.; O'Keeffe, M.; Yaghi, O. M. The chemistry and applications of metal-organic frameworks. Science 2013, 341, 974.

(3) Gamage, N-D. H.; McDonald, K. A.; Matzger, A. J. MOF-5-polystyrene: Direct production from monomer, improved hydrolytic stability, and unique guest adsorption. Angew. Chem., Int. Ed. 2016, 55, 12099-12103.

(4) Alezi, D.; Spanopoulos, I.; Tsangarakis, C.; Shkurenko, A.; Adil, K.; Belmabkhout, Y.;

O'Keeffe, M.; Eddaoudi, M.; Trikalitis, P. N. Reticular chemistry at its best: Directed assembly of hexagonal building units into the awaited metal-organic framework with the intricate polybenzene topology, pbz-MOF. J. Am. Chem. Soc. 2016, 138, 12767-12770.

(5) Mottillo, C.; Friščič, T. Carbon dioxide sensitivity of zeolitic imidazolate frameworks. Angew. Chem., Int. Ed. 2014, 53, 7471-7474.

(6) Lu, K.; He, C.; Guo, N.; Chan, C.; Ni, K.; Weichselbaum, R. R.; Lin, W. Chlorin-based nanoscale metal-organic framework systemically rejects colorectal cancers via synergistic photodynamic therapy and checkpoint blockade immunotherapy. J. Am. Chem. Soc. 2016, 138, 12502-12510;

(7) Nath, I.; Chakraborty, J.; Verpoort, F. Metal organic frameworks mimicking natural enzymes: A structural and functional analogy. Chem. Soc. Rev. 2016, 45, 4127-4170.

(8) Peng, L.; Zhang, J. L.; Xue, Z. M.; Han, B. X. Highly mesoporous metal-organic framework assembled in a switchable solvent. Nat. Commun. 2014, 5, 5465; 
(9) Dhakshinamoorthy, A.; Asiri, A. M.; García, H. Metal-organic framework (MOF) compounds: Photocatalysts for redox reactions and solar fuel production. Angew. Chem., Int. Ed. 2016, 55, 5414-5445.

(10) Yang, Q. H.; Xu, Q.; Jiang, H. L. Metal-organic frameworks meet metal nanoparticles: synergistic effect for enhanced catalysis. Chem. Soc. Rev. 2017, 46, 4774-4808.

(11) Nguyen, J. G.; Cohen, S. M. Moisture-resistant and superhydrophobic metal-organic frameworks obtained via postsynthetic modification. J. Am. Chem. Soc. 2010, 132, 4560-4561.

(12) Wang, S.; Morris, W.; Liu, Y.; McGuirk, C. M.; Zhou, Y.; Hupp, J. T.; Farha, O. K.; Mirkin. C. A. Surface-specific functionalization of nanoscale metal-organic frameworks. Angew. Chem. Int. Ed. 2015, 54, 14738-14742.

(13) Yang, C.; Kaipa, U.; Mather, Q. Z.; Wang, X. P.; Nesterov, V.; Venero, A. F.; Omary, M. A. Fluorous metal-organic frameworks with superior adsorption and hydrophobic properties toward oil spill cleanup and hydrocarbon storage. J. Am. Chem. Soc. 2011, 133, 18094-18097.

(14) Jiang, Z. R.; Ge, J.; Zhou, Y. X.; Wang, Z. Y. U.; Chen, D. X.; Yu, S. H.; Jiang, H. L. Coating sponge with a hydrophobic porous coordination polymer containing a low-energy $\mathrm{CF}_{3}$ decorated surface for continuous pumping recovery of an oil spill from water. NPG Asia Mater. 2016, 8, e253.

(15) Niyogi, S.; Hamon, M. A.; Hu, H.; Zhao, B.; Bhowmik, P.; Sen, R.; Itkis, M. E.; Haddon, R. C. Chemistry of single-walled carbon nanotubes. Acc. Chem. Res. 2002, 35, 1105-1113;

(16) Hirsch, A. Functionalization of single-walled carbon nanotubes. Angew. Chem., Int. Ed. 2002, 41, 1853-1859;

(17) Yang, S. J.; Park, C. R. Preparation of highly moisture-resistant black-colored metal organic frameworks. Adv. Mater. 2012, 24, 4010-4013. 
(18) Zhang, W.; Hu, Y. L.; Ge, J.; Jiang, H. L.; Yu, S. H. A facile and general coating approach to moisture/water-resistant metal-organic frameworks with intact porosity. J. Am. Chem. Soc. 2014, 136, 16978-16981.

(19) Li, Z.; Zeng, H. C. Armored MOFs: Enforcing soft microporous MOF nanocrystals with hard mesoporous silica. J. Am. Chem. Soc. 2014, 136, 5631-5639.

(20) Liu, Y. Y.; Ng, Z. F.; Khan, E. A.; Jeong, H. K.; Ching, C. B.; Lai, Z. P. Synthesis of continuous MOF-5 membranes on porous alpha-alumina substrates. Microporous Mesoporous Mater. 2009, 118, 296-301.

(21) Huo, J.; Marcello, M.; Garai, A.; Bradshaw, D. MOF-polymer composite microcapsules derived from pickering emulsions. Adv. Mater. 2013, 25, 2717-2722.

(22) Xiao, B.; Yuan, Q. C.; Williams, R. A. Exceptional function of nanoporous metal organic framework particles in emulsion stabilisation. Chem. Commun. 2013, 49, 8208-8210.

(23) Zhang, B. X.; Zhang, J. L.; Liu, C. C.; Peng, L.; Sang, X. X.; Han, B. X.; Ma, X.; Luo, T.; Tan, X. N.; Yang, G. Y. High-internal-phase emulsions stabilized by metal-organic frameworks and derivation of ultralight metal-organic aerogels. Sci. Rep. 2016, 6, 21401.

(24) Zhu, H.; Zhang, Q.; Zhu, S.P. Assembly of a Metal-organic framework into 3D hierarchical porous monoliths using a pickering high internal phase emulsion template. Chem. Eur. J. 2016, 22, 8751-8755.

(25) Liu, C. C.; Zhang, J. L.; Zheng, L. R.; Zhang, J.; Sang, X. X.; Kang, X. C.; Zhang, B. X.; Luo, T.; Tan, X. N.; Han, B. X. Metal-organic framework for emulsifying carbon dioxide and water. Angew. Chem., Int. Ed. 2016, 55, 11372-11376. 
(26) Li, Z. H.; Zhang, J. L.; Luo, T.; Tan, X. N.; Liu, C. C.; Sang, X. X.; Ma, X.; Han, B. X.; Yang, G. Y. High internal ionic liquid phase emulsion stabilized by metal-organic frameworks. Soft Matter 2016, 12, 8841-8846.

(27) Yang, X.-Y.; Chen, L.-H.; Li, Y.; Rooke, J. C.; Sanchezc, C.; Su. B.-L. Hierarchically porous materials: Synthesis strategies and structure design. Chem. Soc. Rev. 2017, 46, 481-558.

(28) Aveyard, R.; Binks, B. P.; Clint, J. H. Emulsions stabilised solely by colloidal particles. Adv. Colloid Interface Sci. 2003, 100, 503-546.

(29) Suzuki, D.; Tsuji, S.; Kawaguchi, H. Janus microgels prepared by surfactant-free pickering emulsion-based modification and their self-assembly. J. Am. Chem. Soc. 2007, 129, 8088-8089.

(30) Tu, F.; Lee, D. Shape-changing and amphiphilicity-reversing janus particles with $\mathrm{pH}-$ responsive surfactant properties. J. Am. Chem. Soc. 2014, 136, 9999-10006.

(31) Sun, D. R.; Fu, Y. H.; Liu, W. J.; Ye, L.; Wang, D. K.; Yang, L.; Fu, X. Z.; Li, Z. H. Studies on photocatalytic $\mathrm{CO}_{2}$ reduction over $\mathrm{NH}_{2}-\mathrm{UiO}-66(\mathrm{Zr})$ and its derivatives: Towards a better understanding of photocatalysis on metal-organic frameworks. Chem. - Eur. J. 2013, 19, 14279-14285.

(32) Chun, J.; Kang, S.; Park, N.; Park, E. J.; Jin, X.; Kim, K. D.; Seo, H. O.; Lee, S. M.; Kim, H. J.; Kwon, W. H. Metal-organic framework@microporous organic network: Hydrophobic adsorbents with a crystalline inner porosity. J. Am. Chem. Soc. 2014, 136, 6786-6789.

(33) Bonnefoy, J.; Legrand, A.; Quadrelli, E. A.; Canivet, J.; Farrusseng, D. Enantiopure peptide-functionalized metal-organic frameworks. J. Am. Chem. Soc. 2015, 137, 9409-9416.

(34) Hou, J. Y.; Luan, Y.; Tang, J.; Wensley, A. M.; Yang, M.; Lu, Y. F. Synthesis of UiO-66$\mathrm{NH}_{2}$ derived heterogeneous copper (II) catalyst and study of its application in the selective aerobic oxidation of alcohols. J. Mol. Catal. A: Chem. 2015, 407, 53-59. 
(35) Lv, G.; Liu, J.; Xiong, Z.; Zhang, Z.; Guan, Z. Selectivity adsorptive mechanism of different nitrophenols on UiO-66 and UiO-66- $\mathrm{NH}_{2}$ in aqueous solution. J. Chem. Eng. Data 2016, 61, 3868-3876.

(36) He, Q.; Chen, Q.; Lü, M.; Liu, X. Adsorption behavior of Rhodamine B on UiO-66. Chin. J. Chem. Eng. 2014, 22, 1285-1290.

(37) Yang, J.; Dai, Y.; Zhu, X. Y.; Wang, Z.; Li, Y. S.; Zhuang, Q. X.; Shi, J. L.; Gu, J. L. Metal-organic frameworks with inherent recognition sites for selective phosphate sensing through their coordination-induced fluorescence enhancement effect. J. Mater. Chem. A 2015, 3, 7445-7452.

(38) Venna, S. R.; Lartey, M.; Li, T.; Spore, A.; Kumar, S.; Nulwala, H. B.; Luebke, D. R.; Rosi, N. L.; Albenze, E. Fabrication of MMMs with improved gas separation properties using externally-functionalized MOF particles. J. Mater. Chem. A 2015, 3, 5014-5022.

(39) Abid, H. R.; Shang, J.; Ang, H. M.; Wang, S. B. Amino-functionalized Zr-MOF nanoparticles for adsorption of $\mathrm{CO}_{2}$ and $\mathrm{CH}_{4}$. Int. J. Smart Nano Mater. 2013, 4, 72-82.

(40) Luu, C. L.; Nguyen, T. T. V.; Nguyen, T.; Hoang, T. C. Synthesis, characterization and adsorption ability of UiO-66-NH2. Adv. Nat. Sci. Nanosci. Nanotechnol. 2015, 6, 025004.

(41) Tai, S. J.; Zhang, W. Q.; Zhang, J. S.; Luo, G. X.; Jia, Y.; Deng, M. L.; Ling, Y. Facile preparation of UiO-66 nanoparticles with tunable sizes in a continuous flow microreactor and its application in drug delivery. Microporous Mesoporous Mater. 2016, 220, 148-154.

(42) Cavka, J. H.; Jakobsen, S.; Olsbye, U.; Guillou, N.; Lamberti, C.; Bordiga, S.; Lillerud, K. P. Zirconium inorganic building brick forming metal organic frameworks with exceptional stability. J. Am. Chem. Soc. 2008, 130, 13850-13851. 
(43) Wang, N.; Xu, Q.; Xu, S. S.; Qi, Y. H.; Chen, M.; Li, H. X.; Han, B. X. High-efficiency exfoliation of layered materials into 2D nanosheets in switchable $\mathrm{CO}_{2} / \mathrm{Surfactant} / \mathrm{H}_{2} \mathrm{O}$ system. Sci. Rep. 2015, 5, 16764.

(44) Hasan, Z.; Jhung, S. H. Removal of hazardous organics from water using metal-organic frameworks (MOFs): Plausible mechanisms for selective adsorptions. J. Hazard. Mater. 2015, 283, 329-339.

(45) Lv, G.; Liu, J.; Xiong, Z.; Zhang, Z.; Guan, Z. Selectivity adsorptive mechanism of different nitrophenols on UIO-66 and UIO-66- $\mathrm{NH}_{2}$ in aqueous solution. J. Chem. Eng. Data 2016, 61, 3868-3876. 